All letters are subject to editing and may be shortened. Letters should be sent to the BJGP office by e-mail in the first instance, addressed to

journal@rcgp.org.uk (please include your postal address). Alternatively, they may be sent by post as an MS Word or plain text version on CD or DVD. We regret that we cannot notify authors regarding publication. Letters not published in the Journal may be posted online on our Discussion Forum. For instructions please visit: http://www.rcgp.org.uk/bjgp-discuss

\section{Pathfinder status and GP commissioning consortia}

If GP-led commissioning is to realise its potential to re-shape the NHS in ways that serve patients better, facilitate care in and around people's homes, and strengthen general practice, GPs and all those working in the NHS need to understand its basic principles. The key rule is that NHS money is now real money. GPs need to be aware that every prescription or referral is a commissioning decision. Until now we hardly felt the consequences of overspending on prescribing and secondary care budgets. How we spend NHS money will now have financial consequences for us. This will revolutionise vocational training when trainees will need much closer scrutiny by practices to ensure they are not wasting money.

We need to teach and demonstrate that:

Value for money $=$ Effectiveness

As 'pathfinder commissioners' we have to ask 'why has the government chosen general practice to be given this prize?'. We believe it reflects an appreciation of two key attributes of general practice:

- GPs are trusted by patients as their advocates; and

- UK general practices are generally effective, efficient, and financially prudent.

The former will test our relationships with some patients and it is vital that legislation explicitly deals with higher-risk patients who could damage budgets. Practices too, will quickly understand that their neighbours can financially threaten the whole commissioning enterprise.

Vision is crucial ${ }^{1}-$ merely saving and making money is not enough. GP-led commissioning consortia could deliver the high quality outcomes needed for a 'liberated' NHS that truly reduces health inequalities while improving value and effectiveness, and controlling costs. We particularly think that GP-led commissioning could help keep vulnerable older people out of hospital where they languish too often. Other visionary possibilities include:

- Improving primary-secondary care dialogue and joint care;

- Care 365 days a year. We are already some way towards this with a 6-dayweek domiciliary GP service for older people in our town of St Helens;

- longer surgery appointments, for example 15-minutes; and

- development of the next generation of leaders of primary care, by using savings to enhance the training of our staff and our successors.

We applaud the College's determination to support the leaders of GP-led commissioning and now we must ensure that we are actually given power and responsibility. If this is done we are confident that English general practice will deliver on the biggest challenge it has ever faced.

\section{John Holden,}

Garswood Surgery, Billinge Road, Garswood, St Helens, WN4 OXD.

E-mail: john@holdens.org.uk

Stephen Cox,

Garswood Surgery, Billinge Road, Garswood, St Helens, WN4 OXD.

\section{REFERENCE}

1. Roland M. What will the white paper mean for GPs? BMJ 2010; 341: c3985.

DOI: 10.3399/bjgp10X544122

\section{The future of medical education in the UK}

The recent editorial by Rees and Stephenson ${ }^{1}$ comes at a most opportune time as the healthcare world, in which our future graduates will work, becomes more dynamic than ever. The editorial clearly outlines the major steps in development and the challenges that anyone involved in healthcare education will expect to face in the near future. However, I feel that one vital component needs greater emphasis, and that is the recognition given to the specialty of medical education.

Having started life as a working GP, and through an interest in training and assessment, I have now become a fulltime consultant in medical education and I feel that I can see the situation from both sides. What still amazes me is that, despite everyone stating very clearly that the future of our health lies in education, how little notice is paid to the support and development of medical education, how little credibility is afforded to publications in medical education journals, and how little attention is paid to high quality research in the subject; truly a Cinderella within the pantomime of academia.

As a medical educationalist, I have a Masters and a Doctorate in the specialty, but still my colleagues in other academic subjects consider me to have opted out, chosen a soft science, gone for an easy option - I can assure everyone, it is not! 